
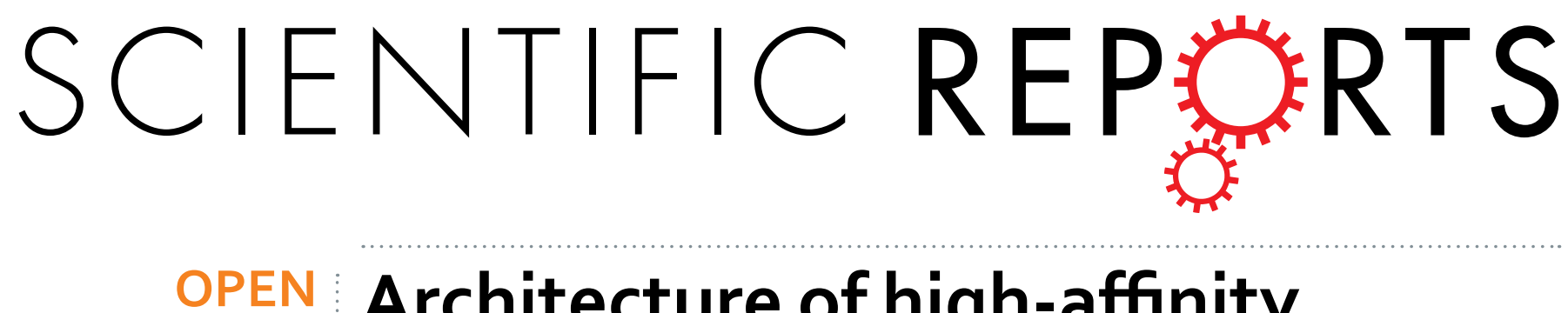

\title{
Architecture of high-affinity unnatural-base DNA aptamers toward pharmaceutical applications
}

Received: 02 July 2015

Accepted: 19 November 2015

Published: 22 December 2015

\author{
Ken-ichiro Matsunaga $a^{1,2,3}$, Michiko Kimoto ${ }^{1,2,3,4}$, Charlotte Hanson ${ }^{5}$, Michael Sanford ${ }^{5}$, \\ Howard A. Young ${ }^{5}$ \& Ichiro Hirao ${ }^{1,2,3}$
}

We present a remodeling method for high-affinity unnatural-base DNA aptamers to augment their thermal stability and nuclease resistance, for use as drug candidates targeting specific proteins. Introducing a unique mini-hairpin DNA provides robust stability to unnatural-base DNA aptamers generated by SELEX using genetic alphabet expansion, without reducing their high affinity. By this method, $>80 \%$ of the remodeled DNA aptamer targeting interferon- $\gamma\left(K_{D}\right.$ of $\left.33 \mathrm{pM}\right)$ survived in human serum at $37^{\circ} \mathrm{C}$ after 3 days under our experimental conditions, and sustainably inhibited the biological activity of interferon- $\gamma$.

In clinical medicine, neutralizing antibodies have revolutionized the treatments of numerous diseases and improved the quality of life for thousands of patients. However, these antibodies occasionally evoke undesirable immune responses to themselves, and quality control in mass production can be problematic ${ }^{1}$. Thus, DNA aptamers represent an alternate approach for targeting proteins ${ }^{2-4}$.

DNA aptamers are oligonucleotides that bind to a variety of targets, such as small molecules, oligosaccharides, peptides, proteins, and cells. They are generated by an evolutionary engineering method called SELEX, using an oligonucleotide library with a randomized sequence ${ }^{5,6}$. Once DNA aptamer sequences are obtained by SELEX, the aptamers can be chemically synthesized on a large GMP scale, for diagnostic and therapeutic applications. Nevertheless, no DNA aptamer drugs have been approved yet for clinical use. Only a modified RNA aptamer (pegaptanib sodium, Macugen) against vascular endothelial cell growth factor-165 (VEGF165) has been approved, as a treatment for neovascular age-related macular degeneration ${ }^{7}$.

As clinical candidates, generated DNA or RNA aptamers are initially screened by their biological activity, based on target affinity, thermal stability, and nuclease resistance. However, the $K_{\mathrm{D}}$ values of most aptamers generated by SELEX are around nM orders, and the aptamers often lack biological activity. Another problem is their low stability against nucleases, and thus the nucleotide components in aptamers must be protected by chemical modifications ${ }^{4,8-12}$, such as $2^{\prime}$-methoxy- and/or 2' -halide-ribonucleotides or $3^{\prime}$-bioconjugated oligonucleotides, which often reduce their affinity and/or increase the production cost. Other versions include RNA aptamers bearing L-ribose with increased nuclease resistance, as reported by Spiegelmer ${ }^{13}$, and DNA aptamers containing modified bases, such as SOMAmer ${ }^{14}$ and X-aptamer ${ }^{15}$, with improved aptamer generation success rates. However, with these methods, the significant augmentation of the aptamer affinities to their targets is still an intractable problem.

We recently developed a new SELEX method to generate high-affinity DNA aptamers, by applying genetic alphabet expansion using an artificial extra base pair (unnatural base pair) ${ }^{16-18}$ between the hydrophobic Ds and Px bases that functions in PCR as a third base pair (SELEX procedure in Fig. 1a). The $K_{\mathrm{D}}$ values of Ds-containing DNA aptamers generated by this method are lower than pM for VEGF165 and $46 \pm 8$ pM for interferon- $\gamma(\text { IFN } \gamma)^{18}$. We now report the high biological activity of the anti-IFN $\gamma$ DNA aptamer in cell culture experiments, and an aptamer remodeling method that greatly increases the thermal stability and nuclease resistance (Fig. 1). The method could open the door to new unnatural-base DNA aptamer drug candidates for clinical trials.
${ }^{1}$ Institute of Bioengineering and Nanotechnology, 31 Biopolis Way, The Nanos, \#04-01, Singapore 138669. ${ }^{2}$ TagCyx Biotechnologies, 1-6-126 Suehiro-cho, Tsurumi-ku, Yokohama, Kanagawa 230-0045, Japan. ${ }^{3}$ RIKEN Center for Life Science Technologies, 1-7-22 Suehiro-cho, Tsurumi-ku, Yokohama, Kanagawa 230-0045, Japan. ${ }^{4}$ PRESTO, JST, Honcho, Kawaguchi-shi, Saitama 332-0012, Japan. ${ }^{5}$ Cancer and Inflammation Program, National Cancer Institute at Frederick, Frederick, MD, 21702 USA. Correspondence and requests for materials should be addressed to I.H. (email: ichiro@ibn.a-star.edu.sg) or H.A.Y. (email:YoungHow@mail.nih.gov) 
a

\section{Unnatural base pair}

\section{SELEX procedure}

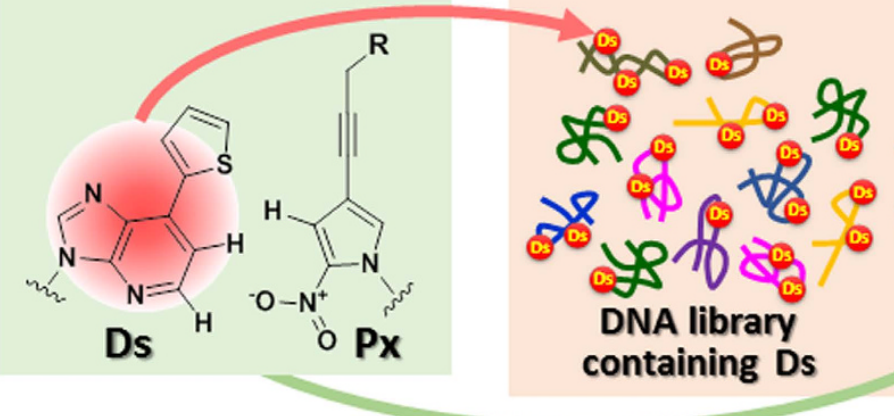

Target protein

Remodeling procedure

(2) Ds-containing DNA aptamer

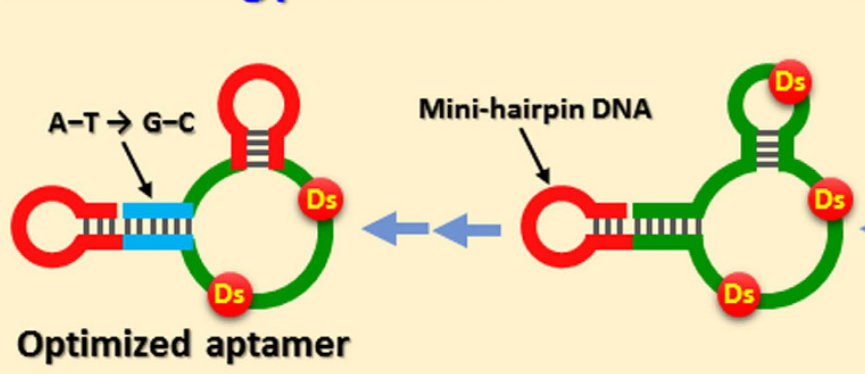

Mini-hairpin DNA

Selection

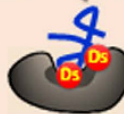

PCR

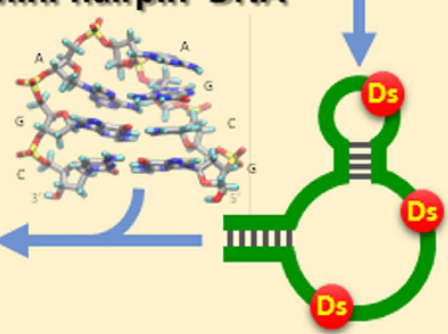

Anti-IFNy aptamer

b

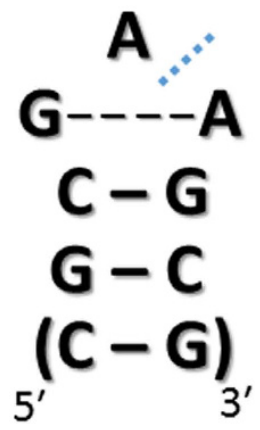

C

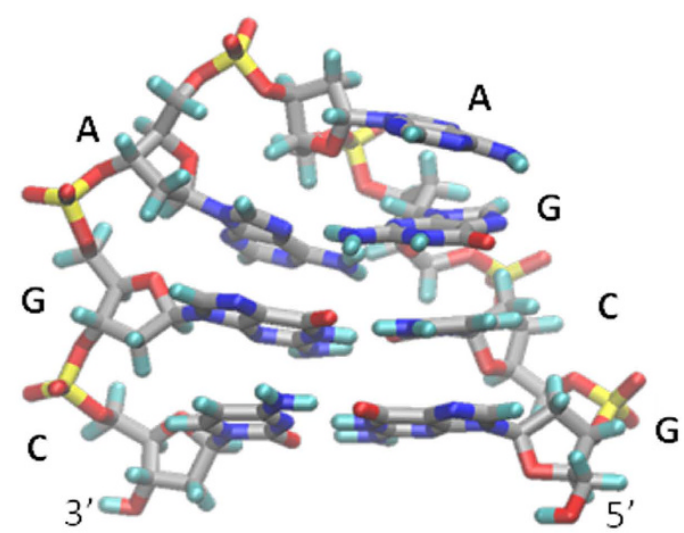

Figure 1. Unnatural-base DNA aptamer generation and remodeling toward diagnostic and therapeutic applications. (a) Generation of unnatural-base DNA aptamers by SELEX involving the Ds-Px pair, and aptamer remodeling strategy by introducing mini-hairpin DNA. The original aptamer sequences are colored green, the mini-hairpin regions are red, and the stem region with $\mathrm{A}-\mathrm{T}$ replaced with $\mathrm{G}-\mathrm{C}$ is blue. (b) The secondary structure of an extraordinarily stable mini-hairpin DNA with a GAA loop and the consecutive two or three $\mathrm{G}-\mathrm{C}$ base pairs as the stem region. The blue dashed line between the two As indicates the kinked position of the GCGAAGC fragment. A non-canonical shared G-A base pair is formed in the GAA loop. (c) The tertiary structure of the mini-hairpin DNA, obtained by NMR spectroscopy ${ }^{22}$.

\section{Results}

Biological activity of the anti-IFN $\gamma$ DNA aptamer. We confirmed that the high affinity of the aptamers to their targets is essential for their biological activity, by inhibition experiments using the unnatural-base DNA aptamer against IFN $\gamma$, a cytokine that induces STAT1 phosphorylation in cultured cells ${ }^{19}$ (Fig. 2a). The mixture of recombinant human IFN $\gamma(2 \mathrm{ng} / \mathrm{ml}, \sim 118 \mathrm{pM}$ as a monomer $)$ and the anti-IFN $\gamma$ DNA aptamer $(50-200 \mathrm{ng} / \mathrm{ml}$, Fig. 3) was added to the human breast tumor cell line in $10 \%$ fetal calf serum, and incubated at $37^{\circ} \mathrm{C}$ for $10 \mathrm{~min}$. The cells were stained intracellularly, using an anti-phospho-STAT1 antibody and FITC-conjugated F( $\left.\mathrm{ab}^{\prime}\right)_{2}$ goat anti-rabbit IgG, and detected by flow cytometry (FACS). The addition of $50 \mathrm{ng} / \mathrm{ml}(\sim 3 \mathrm{nM})$ of the original anti-IFN $\gamma$ DNA aptamer ${ }^{18}\left(49\right.$-mer, aptamer $\left.49, K_{\mathrm{D}}=46 \mathrm{pM}\right)$ completely inhibited the STAT1 phosphorylation (Fig. 2b). In contrast, a conventional DNA aptamer consisting of only the natural bases had no effect (26-mer, 
a

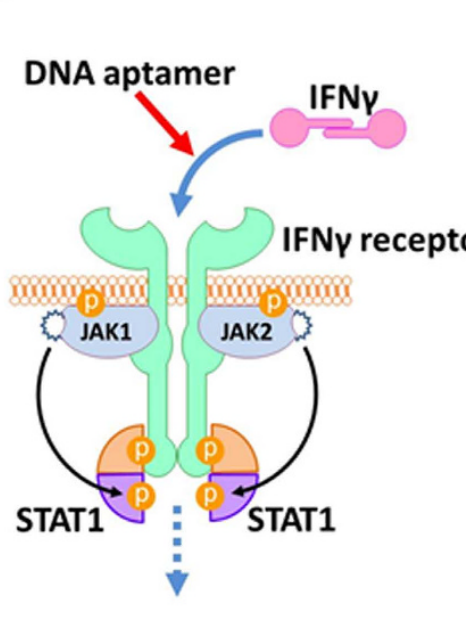

b
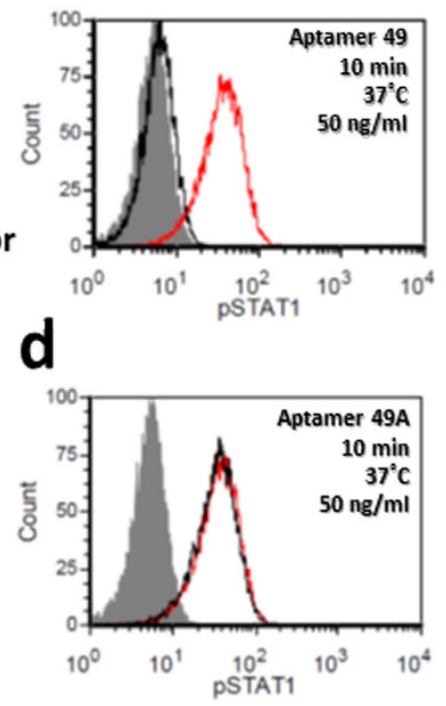

C

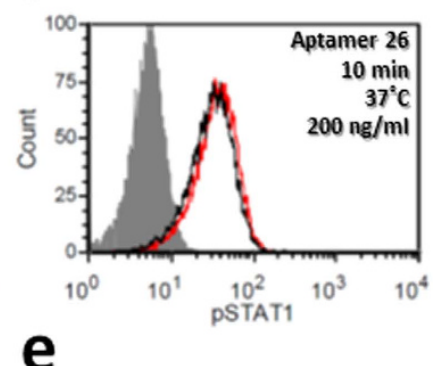

e

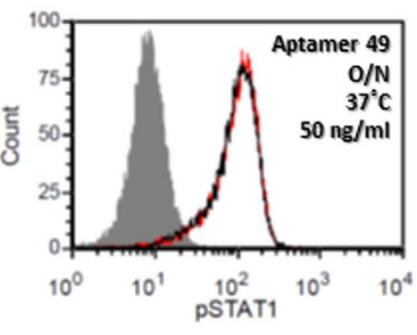

Figure 2. Inhibition of the interaction between IFN $\gamma$ and its receptor by anti-IFN $\gamma$ DNA aptamers. (a) Schematic illustration of the inhibition of the IFN $\gamma$-induced cellular signalling pathway by an anti-IFN $\gamma$ DNA aptamer. (b-e) FACS analysis of STAT1 phosphorylation in the presence of each aptamer. Black and red peaks represent $2 \mathrm{ng} / \mathrm{ml}$ of human IFN $\gamma$ treatment with and without aptamers (b) $50 \mathrm{ng} / \mathrm{ml}$ of aptamer 49 for $10 \mathrm{~min}$, (c) $200 \mathrm{ng} / \mathrm{ml}$ of aptamer 26 for $10 \mathrm{~min}$, (d) $50 \mathrm{ng} / \mathrm{ml}$ of aptamer $49 \mathrm{~A}$ for $10 \mathrm{~min}$, (e) $50 \mathrm{ng} / \mathrm{ml}$ of aptamer 49 overnight), respectively. Grey peaks represent unstimulated cells.
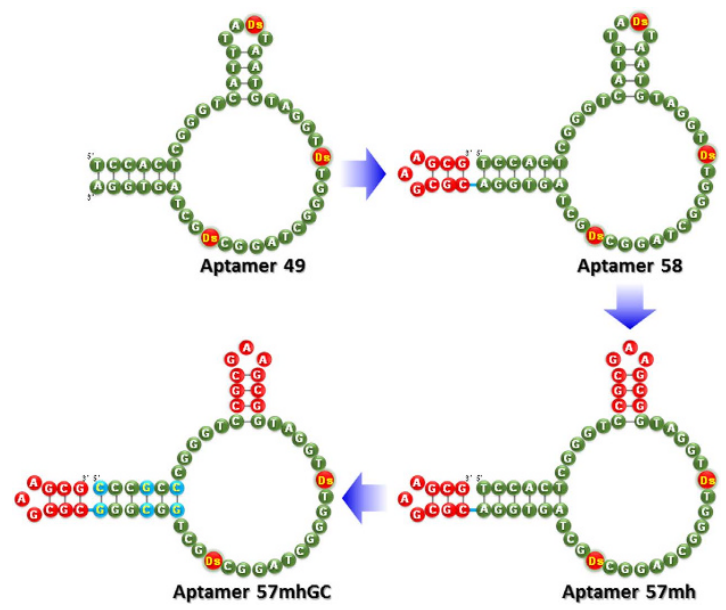

Figure 3. Remodeling strategy of the anti- IFN $\gamma$ DNA aptamer from aptamer 49 to aptamer $57 \mathrm{mhGC}$. The remodeled regions are indicated in red circles with white letters (CGCGAAGCG) and blue circles with yellow letters (A-T replaced with G-C).

aptamer $\left.26, K_{\mathrm{D}}=16 \mathrm{nM}\right)^{20}$ (Fig. 2c). Replacing three Ds bases in aptamer 49 with A (aptamer $49 \mathrm{~A}, K_{\mathrm{D}}=7.2 \mathrm{nM}$ ) also had no inhibitory effect (Fig. $2 \mathrm{~d}$ ). These results revealed that the low $K_{\mathrm{D}}$ values (subnanomolar) are the first threshold for aptamers to exhibit their biological activity and be considered as drug candidates.

The next barrier toward the pharmaceutical application of Ds-containing DNA aptamers is their stability against nucleases. The Ds-containing DNA aptamers are degraded in serum. For example, aptamer 49 was mostly degraded after 24 hours at $37^{\circ} \mathrm{C}$ in human serum (Fig. 4a), and lost the activity in an overnight assay (Fig. 2e). The degradation of aptamer 49 was as high as those of single-stranded DNA fragments consisting of only natural bases (control DNA: ssDNA1 and ssDNA2 50-mer), although a small amount of partially digested fragments of aptamer 49 seemed to remain, as compared to the control DNA fragments (Supplementary Fig. 1). This slight nuclease resistance of aptamer 49 might result from its tertiary structure formation, rather than the incorporated Ds bases. The relatively low thermal stability of aptamer 49 (Thermal melting temperature $\left.\left(T_{\mathrm{m}}\right)=37.8^{\circ} \mathrm{C}\right)($ see Supplementary Fig. 2) might also affect the degradation. 
a

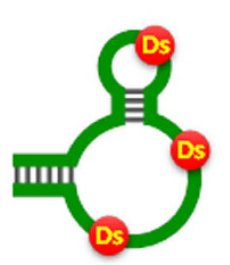

Survival
DNA (\%)

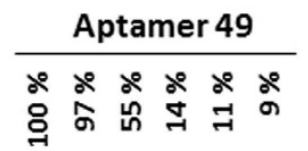

Time (h)

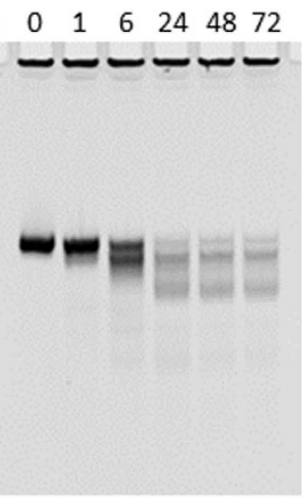

$T_{\mathrm{m}}=37.8^{\circ} \mathrm{C}$
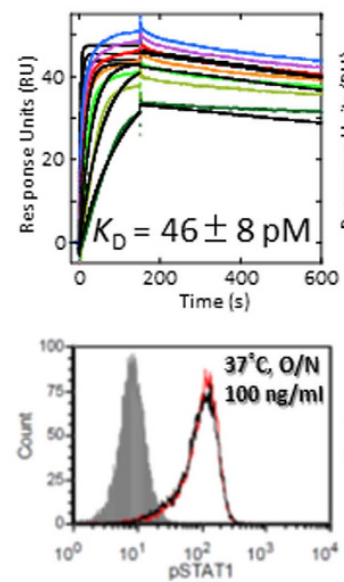
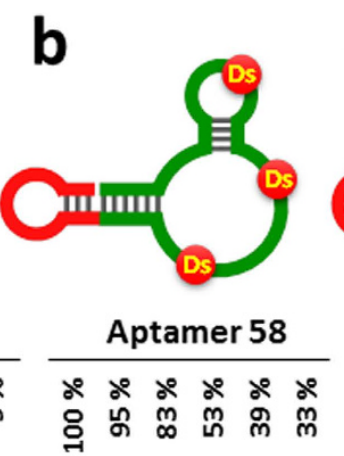

$\begin{array}{llllll}0 & 1 & 6 & 24 & 48 & 72\end{array}$

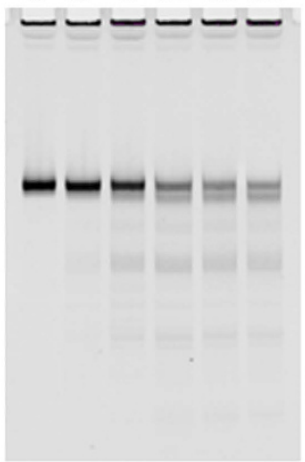

$T_{\mathrm{m}}=43.9^{\circ} \mathrm{C}$
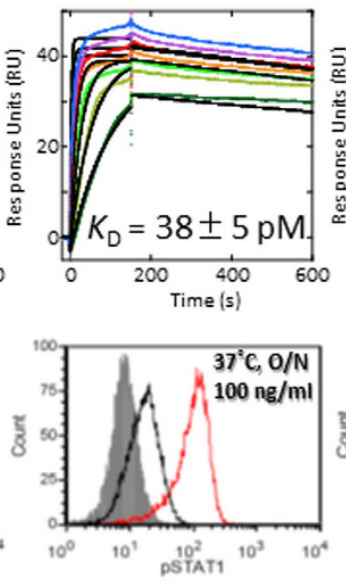

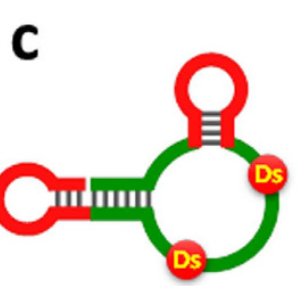

Aptamer 57mh

শ゚ শீ শீ শீ শீ

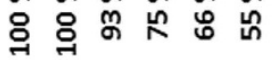

$\begin{array}{llllll}0 & 1 & 6 & 24 & 48 & 72\end{array}$

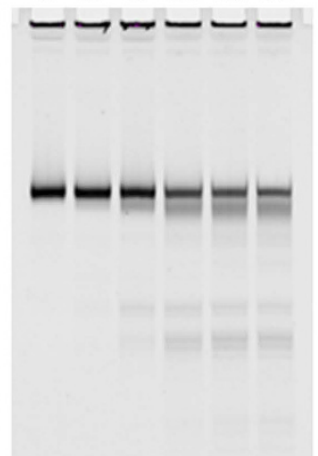

$T_{\mathrm{m}}=51.1^{\circ} \mathrm{C}$
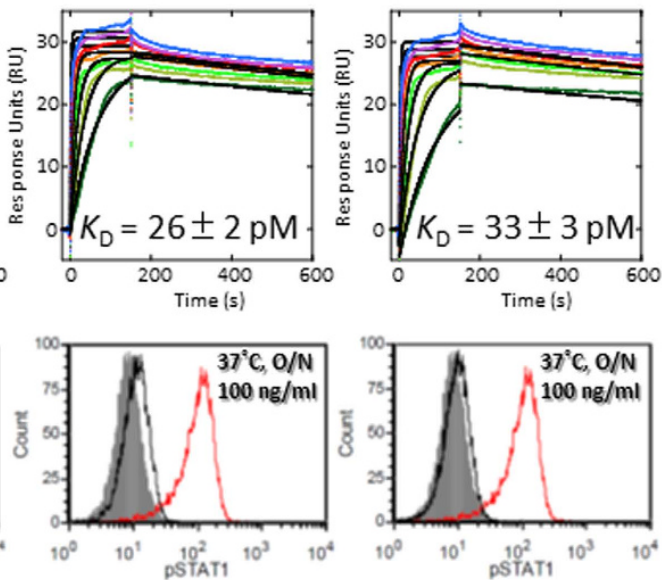

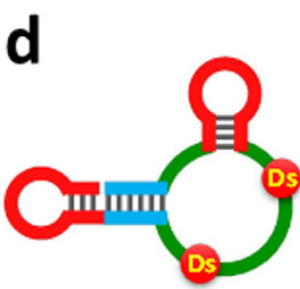

Aptamer 57mhGC 엉으

$\begin{array}{llllll}0 & 1 & 6 & 24 & 48 & 72\end{array}$
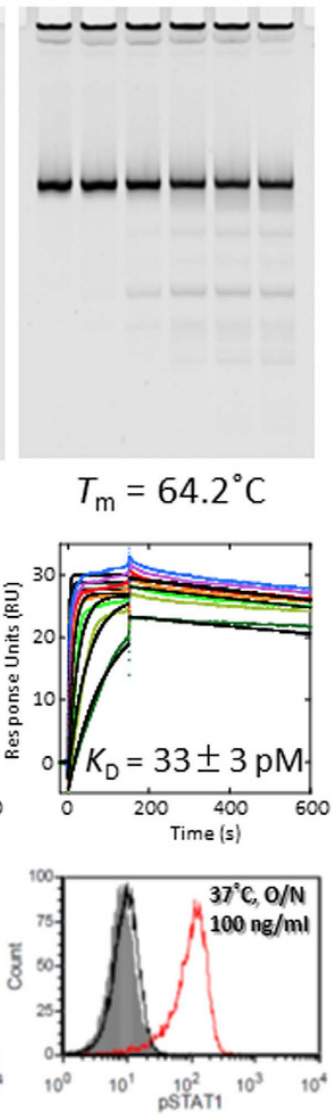

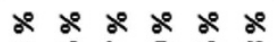

Figure 4. Characterization of the original and remodeled unnatural-base DNA aptamers. (a) Original and (b-d) remodeled anti-IFN $\gamma$ DNA aptamers (a) aptamer 49, (b) aptamer 58, (c) aptamer $57 \mathrm{mh}$, (d) aptamer $57 \mathrm{mhGC}$ ), characterized by nuclease resistance in $96 \%$ human serum at $37^{\circ} \mathrm{C}$ (Supplementary Fig. 3), thermal stability (Supplementary Fig. 2), binding ability analyzed by BIAcore T200 in the presence of 1.25-50 nM IFN $\gamma$ (Supplementary Fig. 5), and STAT1 phosphorylation for the inhibition of IFN $\gamma$ (FACS analysis). Black and red peaks represent human IFN $\gamma$ treatment with and without aptamers, respectively. Grey peaks represent unstimulated cells.

Remodeling the anti-IFN $\gamma$ DNA aptamer by introducing a mini-hairpin DNA. To address the aptamer degradation, we introduced an extraordinarily stable mini-hairpin DNA into the anti-IFN $\gamma$ DNA aptamer. Previously, we discovered unique mini-hairpin DNA sequences consisting of a GNA or GNNA loop $(\mathrm{N}=\mathrm{A}, \mathrm{G}, \mathrm{C} \text { or T) and at least two G-C pairs (Fig. } 1 \mathrm{~b} \text { and } 1 \mathrm{c})^{21-23}$. The $T_{\mathrm{m}}$ value of a GCGAAGC mini-hairpin DNA fragment is as high as $78^{\circ} \mathrm{C}$, and the mini-hairpin DNA fragments are remarkably resistant to nucleases. Furthermore, attaching the mini-hairpin DNA fragment to the $3^{\prime}$-terminus of other oligonucleotides endows resistance against $3^{\prime}$-exonucleases ${ }^{24}$.

Aptamer 49 was remodeled, according to the scheme shown in Fig. 1a (Remodeling procedure), Fig. 3, and Supplementary Table 1. First, a mini-hairpin DNA, CGCGAAGCG, including three G-C pairs and a GAA loop was attached to the $3^{\prime}$-terminus of aptamer 49 (aptamer 58), for resistance to the $3^{\prime}$-exonucleases. Second, the mini-hairpin DNA was replaced with the internal hairpin structure which might not involve the direct interaction with its target (aptamer $57 \mathrm{mh}$ ), to stabilize the entire aptamer tertiary structure and confer endonuclease resistance. 
Our previous studies of aptamer 49 showed that this hairpin loop sequence including Ds is less conserved for the binding ${ }^{18}$. Third, all of the A-T pairs in the terminal stem region were replaced with G-C pairs (aptamer $57 \mathrm{mhGC),}$ to further stabilize the aptamer structure. We presumed that the two Ds bases directly interact with IFN $\gamma$, and other stem or hairpin regions might reinforce the stabilization of the aptamer scaffold.

The high potential of this remodeling strategy was confirmed by the significantly enhanced stability of the aptamer without affinity reduction, as well as the increased endurance of the inhibitory activity to IFN $\gamma$ (Fig. 4). The nuclease resistance and the thermal stability of the remodeled aptamers were improved step by step. In particular, the $T_{\mathrm{m}}$ value of aptamer $57 \mathrm{mhGC}\left(T_{\mathrm{m}}=64.2^{\circ} \mathrm{C}\right)$ increased by $\sim 26^{\circ} \mathrm{C}$, relative to that of aptamer $49\left(T_{\mathrm{m}}=37.8^{\circ} \mathrm{C}\right)$ (Fig. 4 and Supplementary Fig. 2). From the first derivations of the $T_{\mathrm{m}}$ measurements, the characteristic melting profiles of the mini-hairpin regions of aptamer $57 \mathrm{mh}$ and aptamer $57 \mathrm{mhGC}$ were observed at $85-90^{\circ} \mathrm{C}$ (Supplementary Fig. 2). In addition, the $T_{\mathrm{m}}$ curvature of aptamer $57 \mathrm{mhGC}$ was broadened, as compared to the other profiles. Thus, the tertiary structure of aptamer $57 \mathrm{mhGC}$ might melt gradually at certain regions. Importantly, the $T_{\mathrm{m}}$ profiles indicated that aptamer $57 \mathrm{mhGC}$ is much more stable at around $37^{\circ} \mathrm{C}$, relative to the other aptamers. This observation was confirmed by the increased nuclease resistance of the remodeled aptamers (Fig. 4 and Supplementary Fig. 3). Finally, more than $80 \%$ of aptamer $57 \mathrm{mhGC}$ survived after an incubation in serum at $37^{\circ} \mathrm{C}$ for 3 days.

This remodeling did not affect the aptamer affinity to targets, and the $K_{\mathrm{D}}$ value of aptamer $57 \mathrm{mhGC}$ $\left(K_{\mathrm{D}}=33 \mathrm{pM}\right)$ was as high as that of aptamer $49\left(K_{\mathrm{D}}=46 \mathrm{pM}\right)$ (Fig. 4$)$. The chi square values for the determination of the $K_{\mathrm{D}}$ values using a $1: 1$ complex were relatively large, but were reduced by the remodeling process (Supplementary Fig. 4). The chi square values of aptamer 49 were $2.7-4.9$ using a 1:1 complex and 0.6-0.7 using a heterogeneous ligand complex, indicating the possibility that aptamer 49 adopts two structures, a major one with high affinity (pM order $K_{\mathrm{D}}$ value) and a minor one with low affinity (nM order $K_{\mathrm{D}}$ value). In contrast, the chi square value of aptamer $57 \mathrm{mhGC}$ using a $1: 1$ complex was improved (0.6-1.3). Thus, our remodeling method to increase the rigidity of the stem regions might unify the tertiary structure of the aptamer and enhance its stability, without reducing its affinity to targets.

The biological activity was also improved step by step by the remodeling (Fig. 2d, Supplementary Fig. 5). The IFN $\gamma$ inhibition using $100 \mathrm{ng} / \mathrm{ml}(\sim 6.2 \mathrm{nM})$ of aptamers was clearly enhanced by the remodeling. In particular, aptamer $57 \mathrm{mhGC}$ completely inhibited the IFN $\gamma$ activity after an overnight incubation at $37^{\circ} \mathrm{C}$ (Fig. $4 \mathrm{~d}$ ), and even after 3 days (Supplementary Fig. 6).

\section{Discussion}

We have presented the remodeling of high-affinity unnatural-base DNA aptamers, which function as alternatives to antibodies. The remodeled aptamer $57 \mathrm{mhGC}$ targeting IFN $\gamma$, in cases where cytokine expression directly contributes to disease pathogenesis ${ }^{25}$, might be applied to diagnostics and therapeutics. This remodeling process revealed that sub-nM $K_{\mathrm{D}}$ values, as measured by surface plasmon resonance (SPR), might be a pivotal requirement for the use of nucleic acid aptamers in diagnostic and therapeutic applications. To this end, the thermal stabilities of the tertiary structures of unnatural-base DNA aptamers must be increased, to confer nuclease resistance at a physiological temperature. Introducing the Ds bases greatly augmented the aptamer affinity to targets, and remodeling using the mini-hairpin DNA significantly enhanced the thermal stability and nuclease resistance.

Unlike conventional chemical modifications of aptamers, our method using natural oligonucleotides, containing a few low-toxicity Ds bases ${ }^{26}$, has a profound effect on aptamer stability, and thus will provide low-cost drug candidates with minimal toxicity. In addition, the mini-hairpin DNA linkage to the $3^{\prime}$-terminus of the terminal stem region of the aptamers stabilizes them more efficiently, as compared to the conventional $3^{\prime}-3^{\prime}$ inverted dT modification used in pegaptanib sodium for the protection of the $3^{\prime}$-terminus of the aptamer against $3^{\prime}$-exonucleases. The $3^{\prime}$-terminal base of the mini-hairpin DNA also protects the $5^{\prime}$-terminus of the aptamer, by base stacking with the $5^{\prime}$-base of the aptamer (data not shown).

For this remodeling, information about the secondary structures of the aptamers is essential, and can be obtained by doped selection using a library with partially randomized aptamer sequences ${ }^{18}$. Although the base sequences in the stem-loop regions that are essential for direct binding cannot be replaced with mini-hairpin sequences, most of the A-T pairs in the stem regions of aptamers might be replaced with G-C pairs. This is because the stem regions in the Ds-containing DNA aptamers are important as a scaffold to facilitate the interaction of the hydrophobic Ds bases with the target. Thus, this remodeling might be most effective for unnatural-base aptamers, but could also improve the stability and affinity of some conventional DNA and RNA aptamers.

\section{Methods}

Oligonucleotides. DNA fragments were purchased from Gene Design or chemically synthesized with an Oligonucleotide Synthesizer nS-8 (Gene Design), using phosphoramidite reagents for the natural and Ds bases (Glen Research). The DNA fragments were purified by gel electrophoresis.

$T_{\mathrm{m}}$ measurements. UV melting profiles of aptamers were recorded, using a SHIMADZU UV-2450 spectrometer equipped with a temperature controller (TMSPC-8). The absorbance of each sample ( $2 \mu \mathrm{M}$ in $1 \mathrm{mM}$ $\mathrm{KH}_{2} \mathrm{PO}_{4}, 3 \mathrm{mM} \mathrm{Na} \mathrm{HPO}_{4}$, and $155 \mathrm{mM} \mathrm{NaCl}, \mathrm{pH} 7.4$ ) was monitored at $260 \mathrm{~nm}$ from 15 to $95^{\circ} \mathrm{C}$, at a heating rate of $0.5^{\circ} \mathrm{C} / \mathrm{min}$. Each melting temperature was calculated by the first derivative of the melting curve, using the IGOR Pro software (WaveMetrics, Inc.).

Serum stability analyses. Each DNA aptamer (aptamer 49, aptamer 58, aptamer $57 \mathrm{mh}$, and aptamer $57 \mathrm{mhGC}$; final concentration: $2 \mu \mathrm{M}$, the aptamers were initially dissolved in $1 \times \mathrm{PBS}$ ) was incubated in $96 \%$ human serum (Millipore, Lot \#NMM1610699) at $37^{\circ} \mathrm{C}$. Aliquots $(10 \mu \mathrm{l})$ were removed at various time points from 0 to 72 hours, and degradation was terminated by immediate mixing with $110 \mu$ l of denaturing solution $(1 \times$ 
TBE containing $10 \mathrm{M}$ urea). Each sample was fractionated by $15 \%$ denaturing polyacrylamide gel electrophoresis. The DNA was stained with SYBR Gold, detected with a bio-imaging analyzer (Fuji Film LAS-4000), and quantified using the Multi Gauge software to determine the intact fraction. The bands at the top (well positions) on the gel result from the serum, as shown in the lanes without DNA (for only human serum) in Supplementary Fig. 1.

Binding analyses. Binding affinities of DNA aptamers were examined by SPR measurements, using a BIAcore T200 (GE Healthcare) at $25^{\circ} \mathrm{C}$. Each biotinylated DNA aptamer was diluted to $25 \mathrm{nM}$ in phosphate buffer $\left(1 \times \mathrm{PBS} ; 1 \mathrm{mM} \mathrm{KH}_{2} \mathrm{PO}_{4}, 3 \mathrm{mM} \mathrm{Na}_{2} \mathrm{HPO}_{4}\right.$ and $155 \mathrm{mM} \mathrm{NaCl}$, pH 7.4, Gibco), denatured at $95^{\circ} \mathrm{C}$, cooled slowly to room temperature, and then diluted to $0.5 \mathrm{nM}$ in running buffer $(1 \times \mathrm{PBS}$ supplemented with $50 \mathrm{mM} \mathrm{NaCl}$ (final $\mathrm{NaCl}$ concentration: $205 \mathrm{mM}$ ), with $0.05 \%$ ( $\mathrm{vol} / \mathrm{vol}$ ) Nonidet P-40). To reduce the non-specific binding of the protein, such as to the solid-phase support for the measurements, we measured the $K_{\mathrm{D}}$ values with a relatively high $\mathrm{NaCl}$ concentration (Supplementary Fig. 4). Immobilization on a Sensor chip SA (GE Healthcare) was performed by injecting the DNA solution for $8 \mathrm{~min}$, at a flow rate of $5 \mu \mathrm{min}^{-1}$ in running buffer. The interaction between the immobilized DNA aptamer and recombinant human IFN $\gamma$ (Peprotech) was detected by monitoring injections of $1.25 \mathrm{nM}, 2.5 \mathrm{nM}, 5 \mathrm{nM}, 10 \mathrm{nM}, 20 \mathrm{nM}, 30 \mathrm{nM}$, and $50 \mathrm{nM}$ IFN $\gamma$ solutions (diluted with running buffer) in the Kinetic Injection mode. Measurement conditions: flow rate $100 \mu 1 \mathrm{~min}^{-1}$, protein injection time $150 \mathrm{sec}$, and dissociation time $450 \mathrm{sec}$. After each injection, the sensor surface was regenerated with a $5-\mu l$ injection of $50 \mathrm{mM}$ $\mathrm{NaOH}$, and the subsequent refolding of the DNA aptamer was accomplished by equilibration with running buffer for $10 \mathrm{~min}$. To determine the $K_{\mathrm{D}}$ values, control sensorgrams of both a reference cell lacking immobilized DNA fragments on the sensor surface and a measurement with buffer injection were subtracted from each sensorgram of the aptamers, to cancel bulk effects on the sensor chip and response values attributed to nonspecific adsorption, and the data were fitted with a $1: 1$ binding model and a heterogeneous ligand model, using the BIAevaluation T200 software, version 1.0 (GE Healthcare).

Cell lines and IFN $\gamma$ stimulation. The human breast cancer cell line, MDA-MB-231, was maintained in Dulbecco's minimal essential medium (DMEM) (Corning cellgro), supplemented with $10 \%$ fetal calf serum (FCS, Atlanta Biologicals Premium Select Heat inactivated at $56^{\circ} \mathrm{C}$, Cat\#S11550H Lot \# H12123) and $1 \times$ L-glutamine, penicillin, and streptomycin (Gibco). To prepare MDA-MB-231 cells for stimulation, the cells $\left(1 \times 10^{6}\right.$ cells $/ \mathrm{ml}$ in DMEM $/ 10 \% \mathrm{FCS}$ ) were incubated in polystyrene round tubes at $37^{\circ} \mathrm{C}$ for $15 \mathrm{~min}$. The cells were centrifuged at $1,200 \times \mathrm{g}$ for $5 \mathrm{~min}$, and resuspended in DMEM $/ 10 \%$ FCS containing $2 \mathrm{ng} / \mathrm{ml} \mathrm{IFN} \gamma$. The cells were stimulated for $10 \mathrm{~min}$ at $37^{\circ} \mathrm{C}$, centrifuged, washed once in PBS to stop the reaction, and prepared for FACS analysis.

IFN $\gamma$ stimulation in the presence of aptamers. Aptamers were diluted in PBS to a concentration of $10 \mu \mathrm{g} / \mathrm{ml}$ (final volume: $200-300 \mu \mathrm{l}$ ), heated at $70^{\circ} \mathrm{C}$ for $3 \mathrm{~min}$, and then cooled on ice for 1 to $2 \mathrm{~min}$. Before IFN $\gamma$ stimulation, $50-200 \mathrm{ng} / \mathrm{ml}$ aptamer (pre-incubated in DMEM $/ 10 \% \mathrm{FCS}$ at $37^{\circ} \mathrm{C}$ overnight or not) and $2 \mathrm{ng} /$ $\mathrm{ml} \mathrm{IFN} \gamma$ were incubated together at $37^{\circ} \mathrm{C}$ for $10 \mathrm{~min}$ in DMEM/10\% FCS. This mixture was then added to the MDA-MB-231 cells, as described above.

Preparation for FACS Analysis. After stimulation and washing, the cells were resuspended in $1 \mathrm{ml}$ of $2 \%$ paraformaldehyde (Electron Microscopy Sciences) for $10 \mathrm{~min}$ at room temperature, centrifuged, and resuspended in $1 \mathrm{ml}$ of ice-cold $90 \%$ methanol. The cells were incubated for 30 to $60 \mathrm{~min}$ or up to $72 \mathrm{~h}$ (see Supplementary Fig. 4) at $4{ }^{\circ} \mathrm{C}$ in the dark. After centrifugation, the cells were washed twice with $500 \mu$ l FACS buffer $(1 \times \mathrm{PBS}$ pH 7.4 with $0.1 \%$ sodium azide and $0.1 \%$ BSA), incubated in $100 \mu \mathrm{l}$ of FACS buffer containing $7.5 \mu \mathrm{l}$ of anti-P-Stat-1 (BD Phosflow PE mouse anti-Stat-1 pY701) for 30 to 60 minutes at $4{ }^{\circ} \mathrm{C}$ in the dark, and washed twice with $500 \mu \mathrm{l}$ of FACS buffer. The cells were resuspended in $500 \mu \mathrm{l}$ FACS buffer and analyzed by flow cytometry (De Novo software, FCS Express, version 3).

\section{References}

1. Bradbury, A. \& Pluckthun, A. Reproducibility: Standardize antibodies used in research. Nature 518, 27-29 (2015).

2. Lao, Y. H., Phua, K. K. \& Leong, K. W. Aptamer nanomedicine for cancer therapeutics: barriers and potential for translation. ACS Nano 9, 2235-2254 (2015).

3. Nezlin, R. Aptamers in immunological research. Immunol. Lett. 162, 252-255 (2014).

4. Kong, H. Y. \& Byun, J. Nucleic Acid aptamers: new methods for selection, stabilization, and application in biomedical science. Biomol. Ther. 21, 423-434 (2013).

5. Ellington, A. D. \& Szostak, J. W. In vitro selection of RNA molecules that bind specific ligands. Nature 346, 818-822 (1990).

6. Tuerk, C. \& Gold, L. Systematic evolution of ligands by exponential enrichment: RNA ligands to bacteriophage T4 DNA polymerase. Science 249, 505-510 (1990)

7. Ng, E. W. et al. Pegaptanib, a targeted anti-VEGF aptamer for ocular vascular disease. Nat. Rev. Drug Discov. 5, 123-132 (2006).

8. Green, L. S. et al. Nuclease-resistant nucleic acid ligands to vascular permeability factor/vascular endothelial growth factor. Chem. Biol. 2, 683-695 (1995).

9. Bozza, M., Sheardy, R. D., Dilone, E., Scypinski, S. \& Galazka, M. Characterization of the secondary structure and stability of an RNA aptamer that binds vascular endothelial growth factor. Biochemistry 45, 7639-7643 (2006)

10. Keefe, A. D. \& Cload, S. T. SELEX with modified nucleotides. Curr. Opin. Chem. Biol. 12, 448-456 (2008).

11. Yang, Y., Ren, X., Schluesener, H. J. \& Zhang, Z. Aptamers: selection, modification and application to nervous system diseases. Curr. Med. Chem. 18, 4159-4168 (2011).

12. Dougan, H. et al. Extending the lifetime of anticoagulant oligodeoxynucleotide aptamers in blood. Nucl. Med. Biol. 27, 289-297 (2000).

13. Klussmann, S., Nolte, A., Bald, R., Erdmann, V. A. \& Furste, J. P. Mirror-image RNA that binds D-adenosine. Nat. Biotechnol. 14, $1112-1115$ (1996).

14. Gold, L. et al. Aptamer-based multiplexed proteomic technology for biomarker discovery. PLoS One 5, e15004 (2010).

15. He, W. et al. X-aptamers: a bead-based selection method for random incorporation of druglike moieties onto next-generation aptamers for enhanced binding. Biochemistry 51, 8321-8323 (2012). 
16. Sefah, K. et al. In vitro selection with artificial expanded genetic information systems. Proc. Natl. Acad. Sci. USA 111, 1449-1454 (2014).

17. Malyshev, D. A. et al. A semi-synthetic organism with an expanded genetic alphabet. Nature 509, 385-388 (2014).

18. Kimoto, M., Yamashige, R., Matsunaga, K., Yokoyama, S. \& Hirao, I. Generation of high-affinity DNA aptamers using an expanded genetic alphabet. Nat. Biotechnol. 31, 453-457 (2013).

19. Gonsky, R., Deem, R. L., Young, H. A. \& Targan, S. R. CD2 mediates activation of the IFN-gamma intronic STAT binding region in mucosal T cells. Eur. J. Immunol. 33, 1152-1162 (2003).

20. Tuleuova, N. et al. Development of an aptamer beacon for detection of interferon-gamma. Anal. Chem. 82, 1851-1857 (2010).

21. Hirao, I. et al. Extraordinary stable structure of short single-stranded DNA fragments containing a specific base sequence: d(GCGAAAGC). Nucleic Acids Res. 17, 2223-2231 (1989).

22. Hirao, I. et al. Most compact hairpin-turn structure exerted by a short DNA fragment, d(GCGAAGC) in solution: an extraordinarily stable structure resistant to nucleases and heat. Nucleic Acids Res. 22, 576-582 (1994).

23. Yoshizawa, S., Kawai, G., Watanabe, K., Miura, K. \& Hirao, I. GNA trinucleotide loop sequences producing extraordinarily stable DNA minihairpins. Biochemistry 36, 4761-4767 (1997).

24. Yoshizawa, S. et al. Nuclease resistance of an extraordinarily thermostable mini-hairpin DNA fragment, d(GCGAAGC) and its application to in vitro protein synthesis. Nucleic Acids Res. 22, 2217-2221 (1994).

25. Bian, F. et al. Altered balance of interleukin-13/interferon-gamma contributes to lacrimal gland destruction and secretory dysfunction in CD25 knockout model of Sjogren's syndrome. Arthritis Res. Ther. 17, 53 (2015).

26. Kimoto, M., Moriyama, K., Yokoyama, S. \& Hirao, I. Cytostatic evaluations of nucleoside analogs related to unnatural base pairs for a genetic expansion system. Bioorg. Med. Chem. Lett. 17, 5582-5585 (2007).

\section{Acknowledgements}

This work was supported by a Grant-in-Aid for Scientific Research [KAKENHI 26248043] from the Ministry of Education, Culture, Sports, Science and Technology (I.H.), by grants for projects focused on developing key technologies for discovering and manufacturing drugs for next-generation treatment and diagnosis from the Ministry of Economy, Trade, and Industry (I.H.), by the Japan Science and Technology Agency (JST) Precursory Research for Embryonic Science and Technology (PRESTO) (M.K.), and by the intramural research program of the NIH, National Cancer Institute (H.A.Y.).

\section{Author Contributions}

H.A.Y. and I.H. conceived the project, designed methods and experiments, supervised the project and wrote the manuscript; K.M. and M.K. performed $T_{\mathrm{m}}$ measurements, serum stability analyses, and binding analyses; C.H. and M.S. performed FACS analyses for IFN $\gamma$ inhibition experiments; M.K., K.M., H.A.Y. and I.H. jointly analyzed the data sets; I.H. chemically synthesized oligonucleotides.

\section{Additional Information}

Supplementary information accompanies this paper at http://www.nature.com/srep

Competing financial interests: There is potential competing interest. A patent application describing ideas presented in this article has been filed by TagCyx Biotechnologies and RIKEN. M.K. and I.H. own stock in TagCyx Biotechnologies.

How to cite this article: Matsunaga, K. et al. Architecture of high-affinity unnatural-base DNA aptamers toward pharmaceutical applications. Sci. Rep. 5, 18478; doi: 10.1038/srep18478 (2015).

(c) (i) This work is licensed under a Creative Commons Attribution 4.0 International License. The images (c) or other third party material in this article are included in the article's Creative Commons license, unless indicated otherwise in the credit line; if the material is not included under the Creative Commons license, users will need to obtain permission from the license holder to reproduce the material. To view a copy of this license, visit http://creativecommons.org/licenses/by/4.0/ 